\title{
GENETIC CONTROL OF GLUCOSE PHOSPHATE ISOMERASE IN WHEAT AND RELATED SPECIES
}

\author{
A. J. S. CHOJECKI and M. D. GALE \\ Plant Breeding Institute, Trumpington, Cambridge, U.K.
}

Received 9.viii.82

\section{SUMMARY}

\begin{abstract}
Analysis of glucose phosphate isomerase (GPI) zymograms extracted from grains of wheat aneuploids indicated that the three Gpi- 1 loci each control the production of at least two enzyme subunits. Flat bed isoelectric focussing revealed the 21 possible GPI dimers as 11 discrete bands.

Although no varietal differences were detected in the Gpi-1 products, a null-allele at the Gpi-D1 locus was found in some stocks of Chinese Spring. Analysis of crosses segregating for this $\overrightarrow{0 p i-D} 1 b$ phenotype indicated that the genes encoding the enzyme subunits are closely linked and comprise a compound locus.

GPI zymograms were used to identify homoeologous loci in chromosome additions of rye and Hordeum chilense to wheat, and to confirm the genotypes of chromosome substitutions of Aegilops umbellulata in wheat.
\end{abstract}

\section{INTRODUCTION}

MANY enzyme structural genes have been identified in hexaploid wheat, Triticum aestivum $(2 n=6 x=42)$, by the analysis of electrophoretic zymograms produced from extracts of the appropriate aneuploid lines (Hart, $1979 a$ ). In many cases nullisomic analysis has shown individual enzymes to be encoded by triplicate series of genes on homoeologous chromosomes in the A, B and D genomes. Similar genes with products electrophoretically distinguishable from those in wheat can often be found in different Triticeae species. Thus isozyme analyses can be useful in studying the relationships between wheat and its relatives and in identifying and establishing homoeologies in chromosome addition and substitution lines.

The structural genes of three glucose phosphate isomerases (GPI) are located on the group 1 chromosomes (Hart, 1979b). The involvement of GPI in starch synthesis and breakdown in the wheat grain and the need for more genetic markers for use in analysis of intervarietal crosses and alien-wheat chromosome addition lines has prompted the further investigation of GPI presented in this paper.

\section{MAterials AND Methods}

\section{(i) Genotypes}

\section{(a) Chinese Spring (CS) euploid stocks and aneuploids}

Nullisomic-tetrasomic (NT) and ditelosomic (DT) stocks were used in nullisomic analysis. NT lines lack one homologous pair of chromosomes but are compensated by tetrasomy for another homoeologous pair. DT lines lack a chromosome arm in both of a pair of homologous chromosomes. 
These stocks were developed by Professor E. R. Sears, Missouri University, Columbia and maintained and cytologically checked by T. E. Miller and S. M. Reader at the Plant Breeding Institute (PBI). CS euploid stocks were obtained from T. E. Miller and E. R. Sears. Other euploid lines provided by A. J. Worland (PBI) were reconstituted from monosomic lines developed by E. R. Sears.

\section{(b) Varieties and species}

Forty-six hexaploid T. aestivum varieties, two tetraploid and five diploid Triticeae species from the PBI collection were examined.

\section{(c) Wheat-alien chromosome addition and substitution lines}

Seven addition or substitution series maintained at the PBI were investigated. The recipient varieties, alien species and original sources are given in table 1.

TABLE 1

\begin{tabular}{|c|c|c|c|}
\hline Recipient & Donor & Lines & Original source \\
\hline Chinese Spring & $\begin{array}{l}\text { S. cereale var. } \\
\text { King II }\end{array}$ & $\begin{array}{l}\text { Addns. } 1 R^{\text {cer }} \\
3 R^{\text {cer }}, 4 R^{\text {cer }}, \\
5 R^{\text {cer }}, 6 R^{\text {cer }} \text {. }\end{array}$ & $\begin{array}{l}\text { Chapman et al. } \\
\text { (1974) }\end{array}$ \\
\hline Chinese Spring & $\begin{array}{l}\text { S. cereale var. } \\
\text { Imperial }\end{array}$ & $\begin{array}{l}\text { Addns. } 1 R^{\text {cer }} \\
2 R^{\text {cer }}, 3 R^{c e r} \\
4 R^{\text {cer }}, 5 R^{\text {cer }}, \\
6 R^{\text {cer' }}, 7 R^{\text {cer' }}\end{array}$ & $\begin{array}{l}\text { Driscol and Sear } \\
\text { (1971) }\end{array}$ \\
\hline Chinese Spring & S. montanum & $\begin{array}{l}\text { Addns. } 1 \mathrm{R}^{\text {mon }} \\
2 \mathrm{R}^{\text {mon }}, 4 \mathrm{R}_{\text {mon }} \\
5 \mathrm{R}^{\text {mon }}, 6 \mathrm{R}^{\text {mon }}\end{array}$ & $\begin{array}{l}\text { Chapman et al. } \\
\text { (1974) }\end{array}$ \\
\hline Holdfast & $\begin{array}{l}\text { S. cereale var. } \\
\text { King II }\end{array}$ & $\begin{array}{l}\text { Addns. } 1 R^{\text {cer }}, \\
2 R^{\text {cer }}, 4 R^{\text {cer }} \\
5 R^{\text {cer }}, 6 R^{\text {cer }}, \\
7 R^{\text {cer }}\end{array}$ & $\begin{array}{l}\text { Riley and Chapn } \\
\text { (1958) }\end{array}$ \\
\hline Chinese Spring & $\begin{array}{l}\text { Agropyron } \\
\text { elongatum }\end{array}$ & $\begin{array}{l}\text { Addns. I(1E), } \\
\text { II(7E), III(4E), } \\
\text { IV(3E), VII(6E). }\end{array}$ & Dvorak (1980) \\
\hline Chinese Spring & $\begin{array}{l}\text { Aegilops } \\
\text { umbellulata }\end{array}$ & $\begin{array}{l}\text { Addn. B(1U) } \\
\text { Subs. (1A)1U, } \\
\text { (1B)1U, (1D)1U }\end{array}$ & $\begin{array}{l}\text { Kimber 1967) } \\
\text { Chapman et al. } \\
\text { (1975) }\end{array}$ \\
\hline Chinese Spring & $\begin{array}{l}\text { Hordeum } \\
\text { chilense }\end{array}$ & $\begin{array}{l}\text { Addns: disomics } \\
\text { A, B, C, D, E, F } \\
\text { monosomic G, } \\
\text { ditelo-G }\end{array}$ & $\begin{array}{l}\text { Miller } \text { et al. } \\
\text { (1982) }\end{array}$ \\
\hline
\end{tabular}

\section{(ii) Preparation of samples}

Samples were prepared from mature dry grains, developing grains and from grains incubated in the dark for $36 \mathrm{hrs}$ at $24^{\circ} \mathrm{C}$ on moist filter paper in petri dishes. Single incubated and developing grains were macerated by pestle and mortar at $4^{\circ} \mathrm{C}$ in $400 \mu \mathrm{l}$ water/grain, and dry grains were hand-milled before adding distilled water. Samples were left overnight at $2^{\circ} \mathrm{C}$ and then centrifuged for 5 mins at $10,000 \mathrm{xg}$. The supernatant was used directly for isoelectrofocussing (IEF). 
Certain very faint bands observed in zymograms of samples prepared in this way were not seen when an extraction buffer containing 2-mercaptoethanol (2-ME) was used. These bands are probably altered isozymes formed by interaction of sulphydryl groups of cysteine residues of existing isozymes with oxidised glutathione which accumulates in stored samples (Hopkinson, 1970). 2-ME is a sulphydryl reducing agent which reverses these storage changes. It was not generally used in these experiments because it had a deleterious effect on zymogram quality.

\section{(iii) Gel isoelectric focussing (IEF)}

IEF was carried out at $2^{\circ} \mathrm{C}$ using thin-layer polyacrylamide gels (LKB ampholine PAG plates) containing a mixture of carrier ampholytes with isoelectric points (pIs) ranging from $5 \cdot 5$ to $8 \cdot 5$. Electrode strips were soaked in $0.4 \mathrm{M}$ hydroxyethylpiperazine ethylsulphonic acid (HEPES) (anode) and $0.1 \mathrm{M} \mathrm{NaOH}$ (cathode). The gel was prefocussed for $30 \mathrm{mins}$ at $1 \mathrm{~W} / \mathrm{cm}$ gel width, in order to set up the $\mathrm{pH}$ gradient, before applying samples absorbed directly onto paper wicks $(50 \mu \mathrm{l}$ per track) and placed $1 \mathrm{~cm}$ in from the cathode. Power was then re-applied for $2 \frac{1}{2}$ hrs. The sample wicks were removed after 40 mins to prevent tailing by proteins absorbed to the paper. A series of $\mathrm{pH}$ readings along the gel was then taken, using a surface $p \mathrm{H}$ electrode. The enzymes were then refocussed by re-applying power for a further 10 mins.

(iv) Enzyme staining

(a) Glucose phosphate isomerase (GPI)

The method (fig. 1) used was modified from Hart (1979b) and Gottlieb (1977) and included $72 \mathrm{ml} 0.1 \mathrm{M}$ Tris- $\mathrm{HCl}$ buffer ( $p \mathrm{H} \mathrm{8.0)}, 3 \mathrm{ml} \mathrm{0.25} \mathrm{M}$ $\mathrm{MgCl}_{2}, 15 \mathrm{mg}$ fructose-6-phosphate (F6P), 4.5 mg NADP, $3 \mathrm{mg}$ Meldolablau, $7 \mathrm{mg}$ dimethylthiazolyl-diphenyltetrazolium bromide (MTT) and 30 units of glucose-6-phosphate dehydrogenase (G6PD). Staining was carried out in the dark at $37^{\circ} \mathrm{C}$.

\section{(b) 6-phosphogluconate dehydrogenase (6PGD)}

To specifically stain 6PGD, which is also visualised using the GPI stain, the above mixture was modified, by omitting F6P and G6PD, and including $10 \mathrm{mg}$ of 6-phosphogluconate as a substrate (fig. 1).

All chemicals used were obtained from Sigma Chemical Company, except 6-phosphogluconate and Meldolablau which were supplied by Boehringer (BCL).

\section{Results AND DISCUSSION}

(i) Nullisomic analysis

The evaluation of the GPI zymograms (Plate 1, A) of the Chinese Spring NT stocks confirms the location of GPI-1 structural genes as a triplicate set on the homoeologous group 1 chromosomes (Hart, 1979b). Analysis of the zymograms of group 1 DT lines (Plate 1, B) confirms that these genes are located on the short arms of these chromosomes. GPI is 
Fructose-6-phosphate

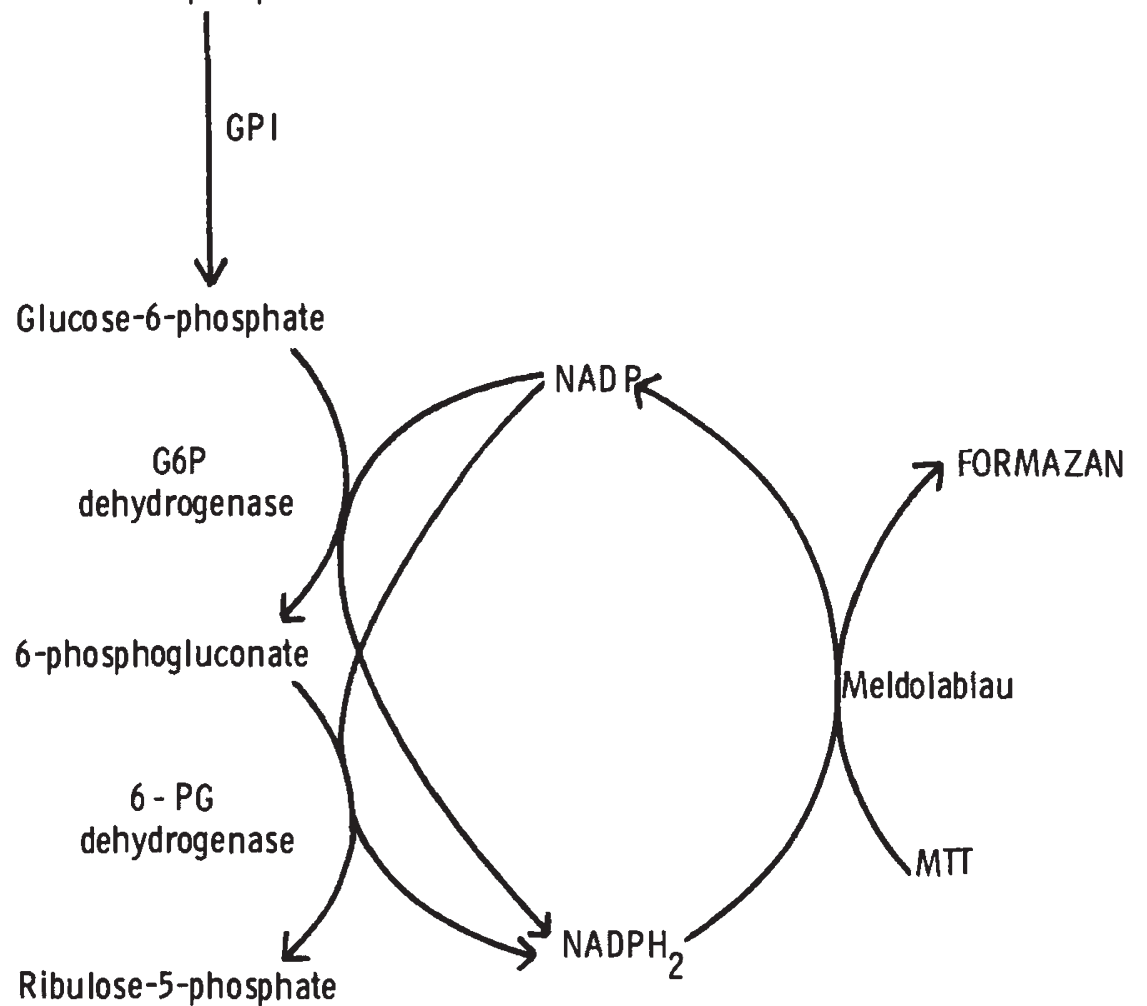

FIG. 1.-Staining system for glucose phosphate isomerase and 6-phosphogluconate dehydrogenase, involving reduction of MTT to form dark blue insoluble formazan.

a dimeric enzyme, as has been shown in various studies in a wide range of organisms (e.g., Gottlieb, 1973; Detter et al., 1968). Eleven major bands are distinguishable in CS (ex E.R. Sears) (Plate 1, A) with pIs ranging from $6 \cdot 1$ to $7 \cdot 3$, of which all but one are removed by the loss of one or other group 1 chromosome. The isozyme patterns resolved in this study cannot be accommodated by Hart's original model of three different GPI protomers forming six possible dimers. However a model (fig. 2) involving two different GPI protomers per group 1 chromosome (six in all) can account for the variation in the CS group 1 NTs in Plate $1, A$, tracks b-g. The model is derived by relating the presence or absence of each band to the presence or absence of a group 1 chromosome (or either of a pair of group 1 chromsomes in the case of allozymes).

The DT 1BS (plate 1, B, track d) gave an anomalous GPI phenotype. This line would be expected to show the full CS isozyme complement but in fact displays a nulli-1D phenotype as in DT-1DL (plate 1, B, track e), a phenomenon also described by Hart (1979b). This is discussed below.

\section{(ii) Diploid and tetraploid species}

To aid the interpretation of the complex GPI phenotype of CS, several diploid and tetraploid species were examined (plate $1 . \mathrm{C}$ ). All the species 
show more than one isozyme indicating that they carry genes controlling production of more than one GPI subunit. At least two protomers, with all the possible homo- and heterodimers, are required to account for the patterns found in the diploids, except that of Ae. speltoides for which at least three protomers are needed. This evidence supports the use of two different protomers per group 1 chromosome in the model described above, since hexaploid wheat is an allopolyploid between three diploid ancestors. The two tetraploids examined have four ( $T$. durum) and six (Ae. ventricosa) major bands, and hence must produce more than two different protomers. Three different protomers forming all the possible homo- and heterodimers would produce a zymogram of six bands. However cofocussing of any of the dimers will produce a zymogram of fewer bands.

Heterodimers have electrophoretic mobilities intermediate to the homodimers whose protomer type they share (Gottlieb, 1977). Assuming that the component protomers are produced at the same rate, and that they randomly and freely combine to form dimers of similar enzyme activity, the relative staining intensities of bands can be predicted. Thus in a simple two protomer situation the heterodimer form should have twice the amount of dimer (and hence twice the staining intensity) of the two homodimer forms.

From the model it is possible to predict the zymograms of the diploid AA, BB and DD genomes and the tetraploid AABB (fig. 2). T. monococcum, Ae. squarrosa and $T$. durum have zymograms predicted for the AA diploid, DD diploid, and the AABB tetraploid genomes respectively. This agrees with the existing evidence for these genome-species relationships (Peterson, 1965). Ae. sharonensis, which from chromosome pairing observations (Tanaka, 1955) is assigned the same genomic symbol as Ae. longissima, has been described as being closely related to the ancestor of the B genome (Kushnir and Halloran, 1981) and here displays a zymogram similar to that predicted for the B genome.

Hart $(1979 b)$ noted that the $1 \mathrm{~B}$ products had a greater activity or were present in larger quantities than the $1 \mathrm{~A}$ and $1 \mathrm{D}$ products, possibly due to a gene duplication. In this analysis band 1, in particular, stains more intensely than predicted; this could indeed be explained by a duplication of the gene(s) coding for the $\beta_{2}$ protomer. However, a concomitant increase in intensity of the $\beta_{1} \beta_{2}$ band (band 3) might be expected, but is not seen, so the possibility of preferential homodimer formation, or differential isozyme activities cannot be overruled.

GPI isozymes differing considerably in catalytic activity (with the hybrid heterodimer having a non-intermediate $\mathrm{K} m$ value) have been described in self-pollinating lines of Clarkia xantiana (Gottlieb and Greve, 1981). Differential effects of temperature on the activity of different GPI isozymes are seen in the sea anemone, Metridium senile, and temperature is suggested as being an important selective agent in maintaining this polymorphism (Hoffmann, 1981).

\section{(iii) Intervarietal variation}

The 46 hexaploid wheat varieties examined in this study, show no variation in GPI phenotype suggesting that the system is highly conserved. The agreement between the zymograms of the modern diploids T. monococcum and Ae. squarrosa and those predicted for the ancestors of the A and 

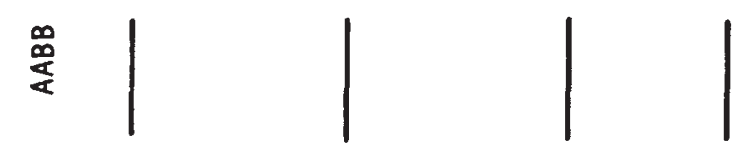

ㅇ
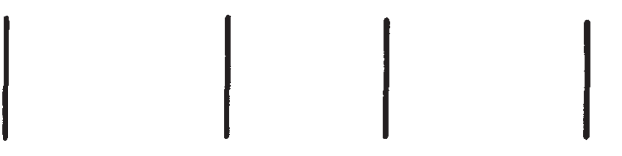

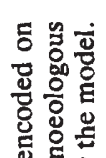

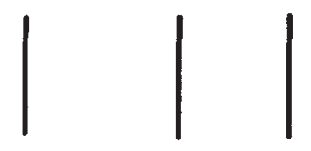

舟岕

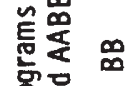

蜜吕

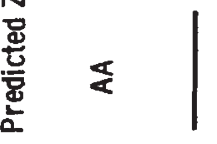

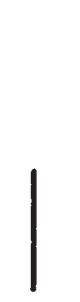

है है

욜

Ẽ

密宫

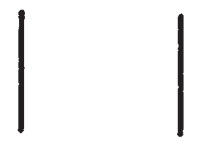

E

政卷

हू

政点

。

E

논

कै 몽

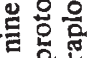

央

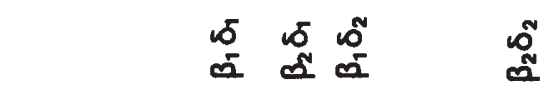

范

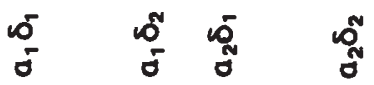

的合

舟它合

흘

क०

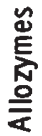

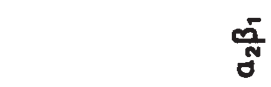

$\frac{\pi}{0}$ व

政

艺发交

믕 읗

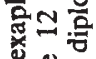

롱

证

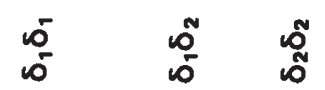

ह

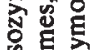

○。

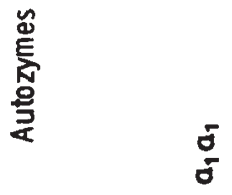

㐫 $\frac{n}{n}$

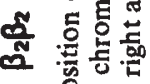

ס̊

:

号这

包

응

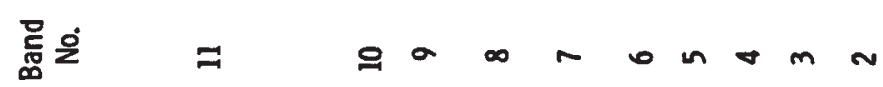

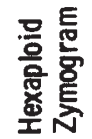

111111111

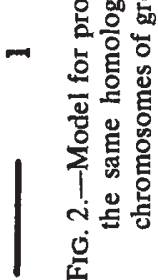


D genomes respectively also indicates that the homoeoallelic variation has been conserved.

Nevertheless a polymorphism does exist among the CS stocks. As noted earlier the CS DT-1BS line has a phenotype similar to CS N1D-T1A and CS N1DT 1B. The same null-1D phenotype has been found in the CS monosomic 1B, in the disomic reconstituted from it, in CS DT-5BS, and in the entire stock of CS euploids maintained at the PBI. The origin of the polymorphism is not clear but it seems likely that the null-1D mutation arose in the monosomic $1 \mathrm{~B}$ line, which may be connected with the DT 1BS stock developed by M. Muramatsu. Subsequently, the PBI euploid stock may have been inadvertently derived from the monosomic $1 \mathrm{~B}$, and it would later have been used in the production of the DT-5BS by T. E. Miller (derivation of DT stocks in Sears and Sears, 1979).

Whatever the origin, the null-GPI-D1 CS phenotype $\left(C^{\prime}\right)$ provides a means of ascertaining linkage within the Gpi-D 1 locus. Some segregating $F_{2}$ progeny from the $C S \times C S^{\prime}$ hybrid are shown in plate $1, D$. Among thirty such progeny no plants were found which showed non-parental zymogram patterns, therefore the genes encoding for the (at least) two $\delta$ protomers must be closely linked. They may have been produced by unequal crossing over with consequent gene duplication and subsequent divergence.

This Gpi-D 1 null-allele is assigned the symbol "b", the Gpi-D $1 a$ allele being that of the original CS stock. The $F_{2}$ shown in plate $1, D$ is comprised of homozygotes for $G p i-D 1 a$ and $G p i-D 1 b$ and heterozygotes; these gene dosage differences $(3,2,1$ or 0$)$ in the triploid endosperm tissue may account for the varying relative intensities, of certain bands, in particular bands 8 and 10 .

\section{(iv) GPI in alien addition/substitution analysis}

Most alien chromosome additions to wheat have been made using CS as the recipient genotype, because of the availability of CS aneuploids. The use of the $\mathrm{CS}^{\prime}$ stock has greatly facilitated the analysis of GPI zymograms of alien addition lines produced at the Plant Breeding Institute.

\section{(a) Rye additions}

The location of the homoeologous loci, Gpi-R 1 on chromosome $1 \mathrm{R}^{\text {mon }}$ of Secale montanum (plate 2, E) and $1 \mathrm{R}^{\mathrm{cer}}$ of Secale cereale var. King II (plate 2, F) was ascertained in CS/S. montanum and CS/King II addition series. These lines were produced at the PBI using the CS' genotype, and against this GPI background, the added rye GPI-R1 dimers, and dimers formed between wheat and rye protomers are clearly visible. The dilution of the rye bands following the formation of such wheat-rye dimers is notable. The homoeology of the King II $1 \mathrm{R}^{\text {cer }}$ chromosome to group 1 of wheat was previously ascertained by Lawrence and Shepherd (1981) on the basis of seed protein genes.

The effect of addition of Gpi-R1 in the presence of Gpi-D1a in Holdfast/King II and CS/Imperial was more difficult to detect because the rye and wheat-rye GPI dimers apparently cofocussed with dimers involving GPI-D1 subunits. 


\section{(b) Agropyron additions}

The presence of $G p i-E g 1$ on the I(1E) addition could not be confirmed in the presence of $G p i-D 1 a$.

\section{(c) Aegilops umbellulata substitutions}

The 1U addition (Kimber, 1967) which displays the full CS GPI genotype plus the Ae. umbellulata isozymes (plate 2, G) was used by Chapman et al. (1975) to produce substitutions from hybrids with the CS group 1 monosomics. In GPI zymograms of all three group 1 substitutions, the appearance of the four Ae. umbellulata dimers (with lower pIs than the wheat isozymes) confirms the presence of $G p i-U 1$ on $1 \mathrm{U}$ and hence the inclusion of this chromosome in the substitution.

In $\mathrm{CS}(1 \mathrm{~A}) 1 \mathrm{U}$ the absence of chromosome $1 \mathrm{~A}$ cannot be confirmed because $1 \mathrm{U}$ bands cofocus with the Gpi-A1 dimers in bands 9 and 11 . Furthermore band 10 is present and must be either a wheat-aegilops heterodimer (not seen elsewhere) or a wheat dimer involving a Gpi-A1 product. In CS(1B)1U, however, not only GPI-B1 but also GPI-D1 bands are absent; this is because the substitution was produced by using the $1 \mathrm{~B}$ monosomic (carrying the $G p i-D 1 b$ allele). The absence of $G p i-D 1$ products in CS(1D)1U confirms this substitution genotype.

Interestingly, with the exception mentioned above in $\mathrm{CS}(1 \mathrm{~A}) 1 \mathrm{U}$, there is no evidence for formation of heterodimers between GPI-1U protomers and those of wheat. This may be due to considerable dissimilarity between the protomers of the two species, preventing dimer formation between them. This is supported by the considerable difference in $p I$ of the Ae. umbellulata isozymes and those of wheat.

\section{(d) Hordeum chilense additions}

The $G p i-H^{\text {ch }} 1$ locus was detected on $\mathrm{CS} / H$. chilense addition $\mathrm{G}$. This supports the group 1 homoeology already suggested for this addition on the basis of its loci for high molecular weight glutenin (Miller et al., 1982). Also a ditelosomic addition was identified as carrying the $G p i-H^{c h} 1$ locus (plate 2, H, track b).

The addition was available only as a monosomic, and the GPI isozomes extracted from distal endosperm halves of selfed progeny segregating for the $H$. chilense chromosome are shown in plate $2, \mathrm{H}$. A disomic addition would have the same zymogram as track $b$, monosomic additions are identified in tracks $\mathrm{d}, \mathrm{e}, \mathrm{f}$ and $\mathrm{i}$, and the $H$. chilense chromosome was not transmitted to the grains from which samples in tracks $c, g, h, j, k$ and $\mathbf{l}$ were prepared. Plants grown from the remaining halves of these grains were used to confirm these results by cytological examination of meiotic chromosomes.

\section{(v) Developmental effects on grain GPI}

A series of grain samples, taken at different times during grain development, were analysed to ensure that the results were not confounded by the presence of other Gpi loci which may be active only at specific times. 
Such a situation exists for $\alpha$-amylase where the grain enzyme comprises the products of the developmental specific $\alpha-A m y-1$ and $\alpha-A m y-2$ gene series (Gale et al., 1983, in press).

The CS (Gpi-D $1 a)$ and CS' (Gpi-D $1 b)$ GPI genotypes at eleven sampling dates are shown in plate 2 , I. While no qualitative developmental effects are apparent, quantitative differences are seen in both genotypes. While some of this may be attributable to dimer instability in dry grain, the effects seen in developing grain may reflect differential regulation of some Gpi genes, possibly connected to specific functions of GPI in sugar metabolism.

\section{(vi) 6-phosphogluconate dehydrogenase (6PGD)}

Activity at the most anodal end of the gel, involving bands with $\mathrm{pIs}$ of less than 5.4 were observed in some gels (e.g., plate 2 , I). The bands were observed in samples prepared from germinated or developing grain (before 44 days post anthesis). They were occasionally faintly present in dry grain, but not at all in samples prepared from distal endosperm halves dissected from germinated grain (plate $2, \mathrm{H}$, tracks $\mathrm{c}-1$ ). This may be the zone of activity which Hart (1979b) referred to as GPI-2. Specific staining of 6PGD visualised bands focussing at the same pIs as these bands, but none in the region stained by the GPI specific stain. That the GPI stain can also stain 6PGD was noted by Hart (1979b) and de Lorenzo and Ruddle (1969). Hence, it is reasonable to consider these low $p I$ bands to be 6PGD.

6PGD is an enzyme of the pentose-phosphate pathway of glucose catabolism, which is an important source of NADPH needed for reductive biosyntheses. Such biosynthetic activity would be expected in growing tissue such as developing grain or the germinated embryo, but not in the endosperm of germinated grain where degradative reactions are occurring and indeed this is reflected by the pattern of 6PGD activity described here. No variation in this region was observed among the group $1 \mathrm{NTs}$, nor in NT lines of the other homoeologous groups. The presence of triplicate sets of 6PGD genes on more than one homoeologous group in wheat could account for the difficulty in making chromosomal locations by nullisomic analysis. Rao and Rao (1980) report the location of 6PGD structural gene(s) on rye chromosomes $4 R^{\text {cer }}$ and $6 R^{\text {cer }}$.

\section{Conclusions}

These studies demonstrate that GPI exists in wheat as a complex system of dimers formed from protomers encoded on the short arms of the group 1 chromosomes. There are at least two different protomers per group 1 chromosome, probably produced by compound loci resulting from gene duplication and subsequent divergence, similar to that seen in the genetic control of $\alpha$-amylase (Gale et al., 1983, in press), $\beta$-amylase (Gale et al., 1982 , in press) and high molecular weight glutenins (Payne et al., 1981). Unlike $\alpha$ - and $\beta$-amylase, however, the GPI system appears to be highly conserved, showing no variation among a wide range of varieties of $T$. aestivum hexaploid wheat (except $\mathrm{CS}^{\prime}$ ) and no divergence of the alleles of the component genomes from the diploid ancestors. The reasons for this are not clear but there may be strong selection pressure to maintain the 
system. This kind of analysis is of considerable use in establishing homoeologous wheat-alien relationships in addition and substitution lines. Isozyme analysis also can provide a rapid means of recognising alien chromosomes, in this case for group 1 homoeologues, and as such can substitute for much time-consuming cytological methods of identification. The existence of the polymorphism at the Gpi-D1 locus will enable intrachromosomal mapping of this locus and its subsequent use as a gene marker for chromosome $1 \mathrm{D}$.

Acknowledgements.-The authors thank T. E. Miller and S. M. Reader of the Plant Breeding Institute for cytological verification of the material used in this investigation, and B. C. Allen and K. J. Collett for the photographic work. The senior author is grateful to Imperial Chemical Industries for a Research Studentship.

\section{REFERENCES}

Chapman, V., Riley, R., AND Miller, T, E. (1974). Annual Report of the Plant Breeding Institute 1973, p. 143.

Chapman, V., Miller, T. E., AND RILey, R. (1975). Annual Report of the Plant Breeding Institute 1974, pp. 125-126.

DE LORENZO, R. J., AND RUDDLE, F. H. (1969). Genetic control of two electrophoretic variants of glucosephosphate isomerase in the mouse (Mus musculus). Biochem. Genet., 3,151 .

DETTER, J. C., WAYS, P. O., GIBLETT, E., BAUGHAN, M., HOPKINSON, D., POVEY, S., AND HARRIS, H. (1968). Inherited variations in human phosphohexose isomerase. Ann. Hum. Genet., 31, 329-338.

DRISCOLL, C. J., AND SEARS, E. R. (1971). Individual addition of chromosomes of "Imperial" rye to wheat. Agronomy Abstracts, p. 61971 ,

DVORAK, J. AND KNOTT, D. R. (1974). Disomic and ditelosomic additions of diploid Agropyron elongatum chromosomes to Triticum aestivum. Canad. J. Gen. Cytol., 16, 399-417.

GALE, M. D., LAW, C. N., CHOJECKI, A. J. S., AND KEMPTON, R. A. (1983). Genetic control of $\alpha$-amylase production in wheat. (In press.)

GALE, M. D., AINSWORTH, C. C., AND BAIRD, S. (1982). $\beta$-amylase isozymes in wheat. I. Gene locations in hexaploid varieties. In press.

GOTTLIEB, L. D. (1973). Enzyme differentiation and phylogeny in Clarkia franciscana, C. rubicunda and C. amoena. Evolution, 27, 205-214.

GOTTLIEB, L. D. (1977). Evidence for duplication and divergence of the structural gene for phosphoglucoisomerase in diploid species of Clarkia. Genetics, 86, 289-307.

GOTTLIEB, L. D., AND GREVE, L. C. (1981). Biochemical properties of duplicated isozymes of phosphoglucose isomerase in the plant Clarkia xantiana. Biochem. Genet., 19, 155-172.

HART, G. E. (1979a). Genetical and chromosomal relationships among the wheats and their relatives. Stadler Symp., University of Missouri, Columbia, vol, 11, 9-29.

HART, G. E. (1979b). Evidence for a triplicate set of glucosephosphate isomerase structural genes in hexaploid wheat. Biochem. Genet. 17, 585-598.

HOFFMAN, R. J. (1981). Evolutionary genetics of Metridium senile. I. Kinetic differences in phosphoglucose isomerase allozymes. Biochem. Genet., 19, 120-144.

HOPKINSON, D. A. (1970). The investigation of reactive sulphydryls in enzymes and their variants by starch-gel electrophoreses: studies on the human phosphohexose isomerase variant $\mathrm{pH}$ 15-1. Ann. Hum. Genet., 34, 79.

KIMBER, G. (1967). The addition of the chromosomes of Aegilops umbellulata to Triticum aestivum (var. Chinese Spring). Genet. Res., Camb., 9, 111-114.

KUSHNiR, U., AND HALloRAN, G. M. (1981). Evidence for Aegilops sharonensis Eig. as the donor of the B genome of wheat. Genetics, 99, 495-512.

LAWRENCE, G. J., AND SHEPHERD, K. W. (1981). Chromosomal location of genes controlling seed proteins in species related to wheat. Theor. Appl. Genet., 59, 25-31.

MILLER, T. E., READER, S. M., AND CHAPMAN, V. (1982). The addition of Hordeum chilense chromosomes to wheat. Induced variability in plant breeding. EUCARPIA, International Symposium, 1981, Wageningen. Publ. PUDOC., pp. 79-81.

PETERsON, R. F. (1965). Wheat, Chapter IV. Publ. Leonard Hill, 1965. 


\section{Plate I}
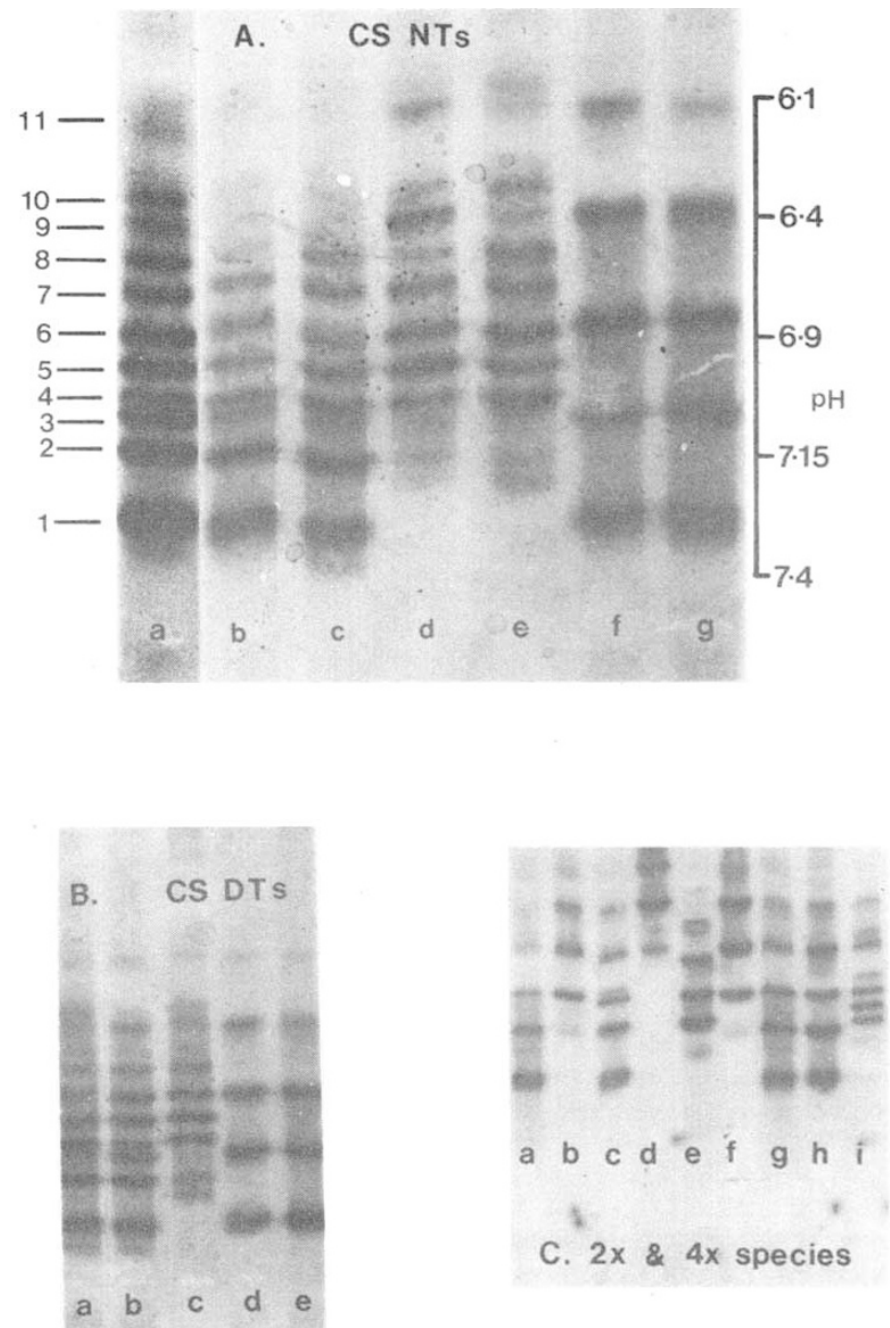

continued over] 


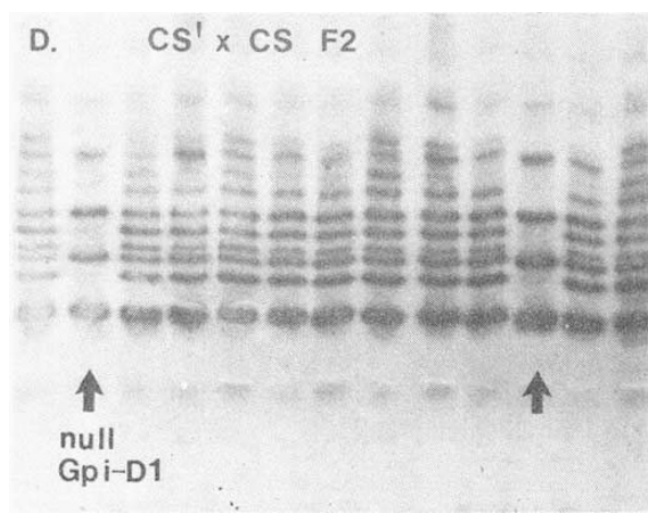

Plate 1

(A) Zymograms of group 1 nullisomic tetrasomics (NT) of Chinese Spring (CS) with idealised euploid CS zymogram at left and $p \mathrm{H}$ gradient at right. Track a. Euploid CS, b. N1A T1B, c. N1A-T1D, d. N1B-T1A, e. N1B-T1D, f. N1D-T1A, g. N1D-T1B.

(B) Zymograms of group 1 ditelocentrics (DT) of CS. Track a. DT-1AL, b. DT-1AS, c. DT-1BL, d. DT-1BS, e. DT-1DL.

(C) Zymograms of diploid and tetraploid Triticeae species. Track a. Aegilops sharonensis $\left(\mathbf{S}^{\mathrm{d}} \mathrm{S}^{\mathrm{d}}\right)$ b. Ae. longissima (S'S'), c. Ae. speltoides (SS), d. Ae. umbellulata (UU), e. Ae. squarrosa (DD), f. Triticum monococcum (AA), g. T. durum (accession A) (AABB), h. T. durum (accession B) (AABB), i. Ae. ventricosa $\left(\mathrm{DDM}^{\mathrm{T}} \mathrm{M}^{\mathrm{r}}\right)$.

(D) Zymograms of individual $\mathrm{F}_{2}$ progeny of a cross between $\mathrm{CS}$ and $\mathrm{CS}^{\prime}$ (see text), segregating at the Gpi-D1 locus. Gpi-D $1 b$ homozygotes are indicated by arrows. 
Plate II
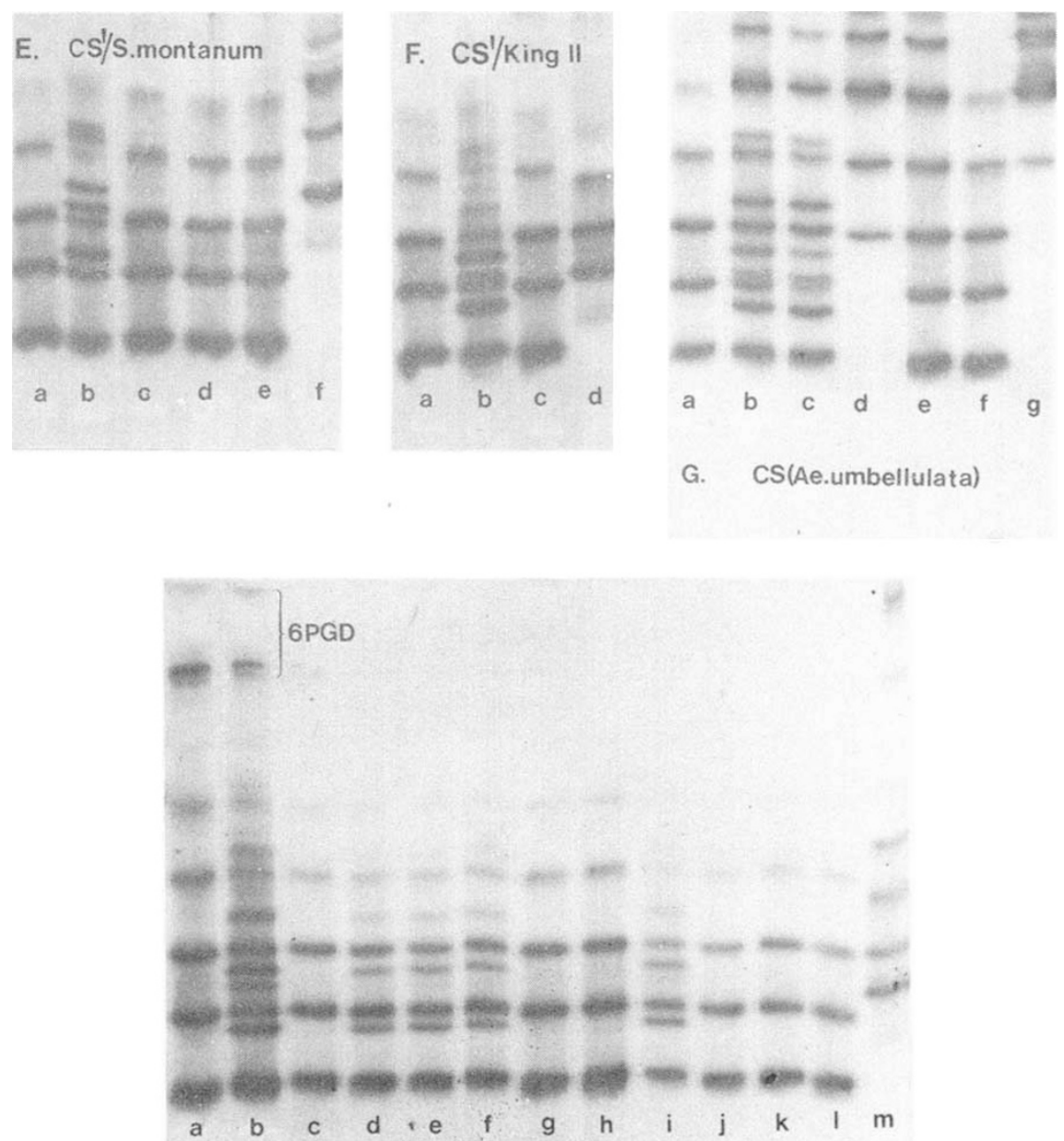

H. Cs $1 /$ H.chilense 


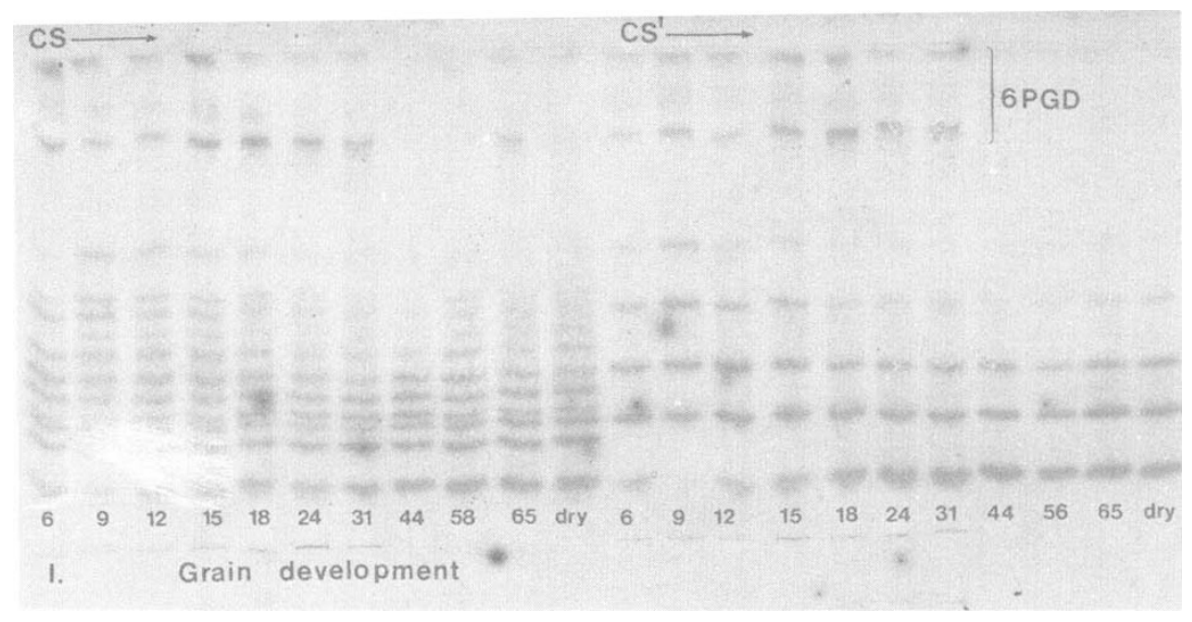

PLATT 2

(E) Chinese Spring (CS' type)/Secale montanum addition lines. Track a. CS', b. Addn. $1 \mathrm{R}^{\mathrm{mon}}$, c. Addni. $2 \mathrm{R}^{\mathrm{mon}}$, d. Addn. $3 \mathrm{R}^{\mathrm{mon}}$, e. Addn. $4 \mathrm{R}^{\mathrm{mon}}$, f. $S$. montanum.

(F) Chinese Spring $\left(\mathrm{CS}^{\prime}\right) /$ Secale cereale var. King II addition lines. Track a. $\mathrm{CS}^{\prime}, \mathrm{b}$. Addn. $1 \mathrm{R}^{\mathrm{cer}}$, c. Addn. $3 \mathrm{R}^{\mathrm{cer}}$, d. S. cereale var. King II.

(G) Chinese Spring/Aegilops umbellulata addition and substitution lines. Track a. CS', b. Addn. B 1U, c. Sub. (1A)1U, d. Sub. (1B)1U, e. Sub. (1D)1U, f. CS', g. Ae. umbellulata.

(H) Chinese Spring (CS' type)/Hordeum chilense addition lines. Track a. CS', b. Ditelosomic addition. G, c-l. individual progeny of selfed monosomic addition $G$, segregating for the $H$. chilense chromosome $\mathrm{G}, \mathrm{m}$. Hordeum chilense.

(I) Zymograms of samples prepared from developing grain of CS and $\mathrm{CS}^{\prime}$ plants taken at eleven sample times as indicated in days post anthesis. 
PAYNE, P. 1., HOLT, L. M., AND LAw, C. N. (1981). Structural and genetical studies on the high-molecular-weight glutenin. Theor. Appl. Gen., 60, 229-236.

RAO, I. N., AND RAO, M. V. P. (1980), Evidence for duplicate genes coding for 6-phosphogluconate dehydrogenase in rye. Genet. Res., Camb., 35, 309-312.

RILEY, R., AND CHAPMAN, V. (1958). The production and phenotypes of wheat-rye chromosome addition lines. Heredity, 12, 301-315.

SEARS, E. R., AND SEARS, L. M. S. (1979). The telocentric chromosomes of common wheat. Proc. 5th Int. Wheat Genetics Symp., 1978, pp. 389-407.

TANAKA, M. (1955). Chromosome pairing in hybrids between Aegilops chinensis and some species of Aegilops and Triticum. Wheat Information Service, 2, 7-8. 